\title{
Effect Of Tamoxifen Treatment On The Epidermal Growth Factor Receptor Expression In The Mouse Ovarian Tissue
}

\author{
Ender Deniz Asmaz ${ }^{1}$, Berrin Z1k ${ }^{1^{*}}$ \\ ${ }^{1}$ Department of Histology Embryology, Faculty of Veterinary Medicine, Uludag University, 16059, Bursa, Turkey
}

Received 02.05.2018 Revised: 15.06.2018 Accepted 03.07.2018

\begin{abstract}
The objective of this study was to investigate the effect of Tamoxifen (TAM) treatment on epidermal growth factor receptor (EGFR) expression in the pubertal mice ovary. In this study, 80 female mice ( 8 week-old) were used. Animals divided four groups; non-injected (control A), injected with TAM's vehicle solution (control B). The mice in groups TAM 0.5 and TAM 1.5 were treated with TAM at a dose 0.5 and $1.5 \mathrm{mg} /$ mouse/day respectively. TAM was dissolved with 10\% ethanol: $90 \%$ corn oil. Mice were given daily subcutaneously injections for 5 days. Ovarian sections were immunostained with EGFR antibody and trichrome staining for examine the general structure. We observed that follicular atresia was increased, follicular cysts were formed in stroma, and interstitial cells were increased with TAM dose treatment. In the present study, there were no significant differences in the EGFR expression in mouse ovary of all groups. EGFR expression was not determined in the granulosa cells. While strong EGFR immunoreaction was observed in the interstitial cells and oocyte cytoplasm, weak EGFR immunoreactions was observed in theca cells of follicles.
\end{abstract}

As a result, it was observed that the administered doses of TAM have not significant influence on EGFR expression.

Key Words: EGFR, Immunohistochemistry, Ovary, Tamoxifen

\section{Introduction}

EGFR is a member of the human epidermal receptor (HER) family, comprising four type I transmembrane tyrosine kinase receptors: EGFR (HER1, erbB-1), erbB-2 (HER2 or Neu), HER3 and HER4. EGFR is the expression product of oncogene c-erbB1 and is structurally subdivided into an extracellular ligand-binding domain, a single lipophilic transmembrane domain, and an intracellular tyrosine kinase domain (Uberall et al. 2008). Upon binding of the ligand to the extracellular domain, EGFR is activated and undergoes homodimerization or heterodimerization, which in turn induces the activation of intrinsic tyrosine kinase and ultimately triggers multiple signaling pathways (Hudson et al. 2009). The signaling pathways activated by EGFR dimerization play a key role in variety cancer cell behaviors, including regulation of cell proliferation, adhesion, migration, invasion, angiogenesis and resistance to apoptosis (Yarden and Pines 2002).

In addition to, EGFR has been identified as a strong prognostic indicator in head and neck, breast, ovarian, cervical, bladder, and esophageal cancers (Herbst and Langer 2002). High EGFR expression has been shown to correlate with poor survival in a range of tumors including non-small cell lung cancer, breast, head and neck, gastric, colorectal, esophageal, prostate, bladder, renal, pancreatic, and ovari- 
an cancers (Arteaga, 2002, Atalay et al. 2003, Bernstein et al. 1999, Salomon et al. 1995). Overexpression of the EGFR protein has been detected in $9 \%-62 \%$ of human ovarian cancers (Lassus et al. 2006, Stadlmann et al. 2006). On the other hand, EGFR plays a role in oocyte maturation, in the folliculogenesis and also stimulates the proliferation and differentiation of granulosa cells in vitro and in vivo (Vlodavsky and Brown1978, Jones et al. 1982, Knecht and Catt 1983, Ashkenazi et al. 2005).

The selective estrogen receptor modulator (SERM) tamoxifen has been used treatment for patients with ER-positive breast cancer in both the early and the advanced/ metastatic stages (Shang and Brown, 2002). Acting as both an estrogen agonist and antagonist, tamoxifen is the most frequently used drug in endocrine therapy of breast cancer (Sunderland and Osborne 1991, Goldrisch and Gelber 1991). It may act as a full estrogen agonist, partial agonist or antagonist depending on the dose, species, sex or target organ (MacGregor and Jordan 1998). Its anti estrogenic effect appears to be related to reduce estrogen receptor levels (Spinelli et al. 1991, Gorodeski et al. 1992) or to inhibit the binding of estradiol (E2) to the estrogen receptor (Jordan and Hoerner 1975). Although tamoxifen acts primarily as an antiestrogen, it also exerts a mild estrogenic effect. It is known to be effective and safe with minimal side effects (Jolles et al. 1990). However, recently it has been found to be associated with various endometrial pathologic conditions and endometrial carcinoma (Bernstein et al. 1999, Clarke et al. 1998, Fisher et al. 1994). Several reports suggest that there may be an association between the tamoxifen exposure and the development of ovarian cysts or even an increased risk of ovarian cancer (Jordan and O'Malley, 2007, Liu et al. 1993). Cancer treatments significantly increase survival, but also cause significant side effects such as ovarian failure and sterility in young patients (Blumenfeld et al. 2002, Fong et al. 2008, Meirow and Nugent 2001). TAM agents commonly used in the premenopausal and menapausal women for adjuvant chemotherapy following breast cancer (Dowsett et al. 2010). TAM treatment may also increase the occurrence of ovarian cancer especially among premenopausal women (Rutqvist et al. 1995). Mostly studies has been investigated that the expression of EGFR in vitro breast cancer cells and in the breast cancer patients who used TAM (Ma et al. 2004, Atalay et al. 2003, Lichtner, 2003). However, in the ovary there is limited information on the effect of different doses of TAM on EGFR expression, which plays an important role in folliculogenesis. Therefore, in this study, it was aimed to determine whether or not the EGFR which plays an important role in folliculogenesis and follicle development of different doses of TAM in mouse ovary.

\section{Materials and Methods}

Animals and experimental protocol

Eighty female BALB/C mice (8 week-old) obtained from the Experimental Animals Breeding and Research Center, Turkey, were used throughout the experiments. The animals were housed five per cage in temperature $\left(20-24{ }^{\circ} \mathrm{C}\right)$, humidity (60-70\%), and lighting (12 h light/dark cycles) controlled conditions and were provided with feed and water ad libitum. The experimental protocols were approved by the Animal Care and Use Committee of Uludag University and were in accordance with the National Institute of Health Guide for the Care and Use of Laboratory Animals (2012-09/04).

Mice were randomly divided into 4 groups. (1) Control group (control A, $n=20$ ), remained without any treatment. (2) Control B group, (vehicle treated, $n=20$ ) received an equal volume of solvent, (3) 0.5 TAM group, $(\mathrm{n}=20)$ received $0.5 \mathrm{mg} / \mathrm{mouse} /$ day of TAM and (4) 1.5 TAM group $(\mathrm{n}=20)$, received $1.5 \mathrm{mg} / \mathrm{mouse} /$ day of TAM. TAM was dissolved in 10\% ethanol: $90 \%$ corn oil and the solution prepared for this dissolution was used for control B $(0.1 \mathrm{ml}$ / mouse). The dissolved TAM was injected into the animals for 5 days in a total of $0.1 \mathrm{ml}$ subcutaneously at a dose of 0.5 $\mathrm{mg} / \mathrm{mouse}$ and $1.5 \mathrm{mg} / \mathrm{mouse}$. TAM was freshly prepared every day before injection. At the end of the treatment, the animals in the proestrus period which is characterized by nucleated and some cornified epithelial cells are present in the vaginal smear were separated and weighed and anesthetized by ether inhalation (Ekambaram et al. 2017). They were sacrificed by cervical dislocation and then right ovaries of each mouse were dissected aseptically.

The ovaries were fixed in $10 \%$ neutral buffered formalin and embedded in paraffin blocks. Five $\mu \mathrm{m}$ thick sections were cut from paraffin blocks, mounted on slides, and dried overnight. After dewaxing and rehydration, sections were stained with immunohistochemistry (IHC) for expression EGFR and by the Crossman's modified trichrome stain (Crossman, 1937) for ovary morphology.

Immunohistochemistry analysis

After dewaxing and rehydration, slides were carried out 
antigen retrieval by boiling sections in microwave oven at $750 \mathrm{~W}$ in sodium citrate buffer (1 M, pH 6.1). After cooling, slides were rinsed with PBS and endogenous peroxidase activity was blocked by $10 \mathrm{~min}$ incubation at room temperature in 3\% $\mathrm{H} 2 \mathrm{O} 2$ solution in distilled water. After blocking with non-immune serum into kit for $30 \mathrm{minu}-$ te to reduce nonspecific antibody binding, sections were incubated with primary antibodies, a rabbit polyclonal antibody to EGFR (sc 03, Santa Cruz, CA, USA) diluted to 1:100 for overnight at $4^{\circ} \mathrm{C}$. The sections were stained using ImPRESS IgG-peroxidase kits (Vector Labs) (cat. No. MP7401), according to the supplier's instructions. Finally, 3.3'-diaminobenzidine (DAB) was used for colour development. After counterstaining with haematoxylin, specimens were dehydrated and mounted. Slides processed without primary antibodies were included for each staining as negative control.

Quantitative evaluated according to the staining intensity as follows: no staining (negative, -), slight brown (weak, + ), brown-yellow (moderate, ++ ), and dark brown (strong, $+++)$. The accumulated score of the positive staining represented the relative expression of the protein (Fromowitz et al. 1987, Ergin et al. 2008).

\section{Results}

Histological Findings

During experimental study, the dead was not observed in the animals of control and experimental group. When the ovarian tissues of control and experimental groups were examined, there were not found pathological findings. In the TAM treatment groups, it was observed that the cortex and medulla distinction on the surface of the ovary was significant, the interstitial area was wide, and especially antral follicles were less in experimental groups than in the control groups. Furthermore, it was determined that the corpus luteum was very low on the surface of the ovarium in the TAM treatment groups (Fig. 1A, B). In some of the healthy follicles, a small number of granulosa cells showed an apoptotic structure with spilling into the antrum, but most of the granulosa cells in the follicle were well organized and the cell membrane integrity was not deteriorated. Based on this morphological evaluation, in the experimental groups according to the control group, the presence of small cystic structures in the medulla region and presence of atretic follicles with depending on the dose on the surface of the ovary were observed (Fig. 1B). As a result of evaluation, no atresia was observed in primordial and primary follicles in all groups, but atretic follicles were observed in some secondary, preantral and antral follicles, especially in experimental group compared to control group.

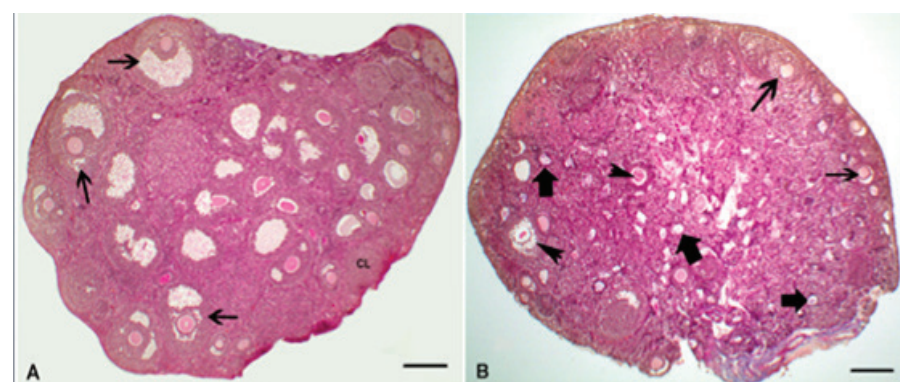

Fig.1. Overview of the ovary; A; Control A group, B; 1.5 TAM group. Healthy follicle (thin arrow), Atretic follicle ( arrow head), cystic structure (thick arrow), corpus luteum (CL). Trichrome staining, Bar: $200 \mu \mathrm{m}$.

\section{Immunohistochemical Findings}

EGFR immunoreactivity was detected in the ovaries of control and experimental groups. Generally, EGFR showed an intracytoplasmic staining in the cell with different staining intensities. EGFR showed a negative immunoreaction

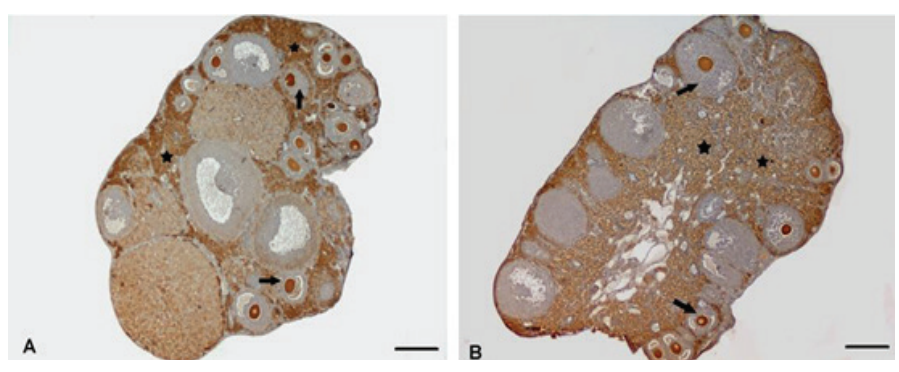

Fig. 2. A; EGFR expression in control A group ovary B; EGFR expression in 1.5 TAM group ovary. Strong EGFR immunoreactivity in interstitial cells (star), Negative EGFR expression in granulosa cells (arrow), IHC staining. Bar: $200 \mu \mathrm{m}$

in the germinative epithelium, which is formed of single layer columnar cells in the ovaries of the control and experimental groups (Fig. 2A, B). In addition, strong immunopositive reaction was detected in oocyte cytoplasm of follicles in all groups (Fig. 3). EGFR expression was not determined in the granulosa cells of healthy and atretic follicles in the ovaries of all groups. A strong EGFR expression was determined in the interstitial cells as well as oocyte cytoplasm in the all groups (Fig. 2B). In theca cells of the follicles in the all groups, a weakly intensity EGFR expression was observed (Fig. 3). Depending on the developmental stages of the corpus luteum was observed moderate intensity of EGFR expression in the ovary of the control group. Also corpus luteum was observed to moderate intensity of EGFR 


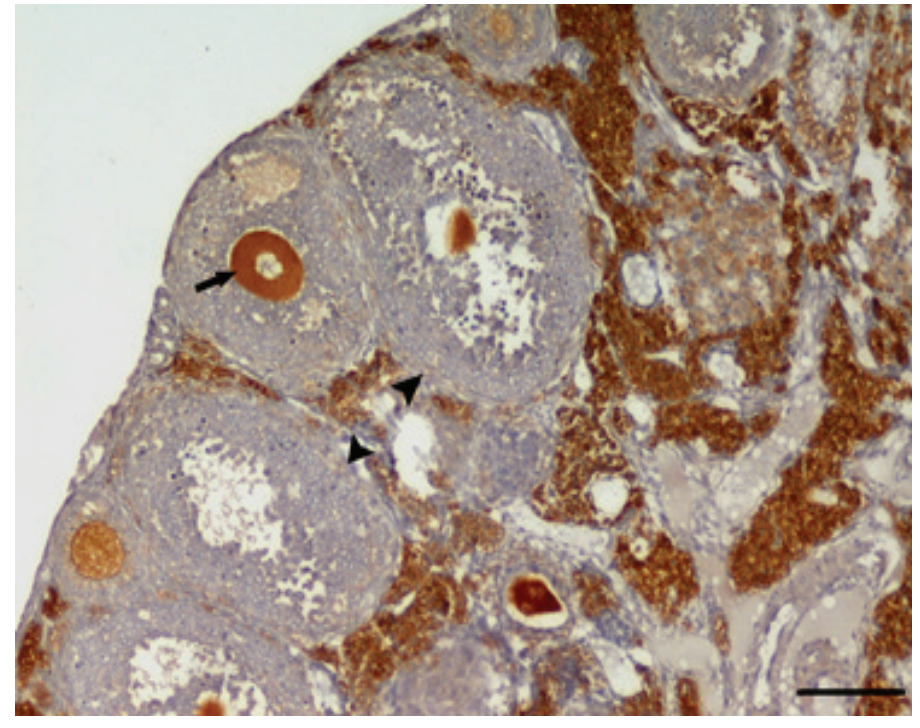

Fig. 3. Strong EGFR expression in oocyte cytoplasm (arrow) and weak EGFR immunoreaction in theca cells (arrow head). IHC staining Bar: $100 \mu \mathrm{m}$.

expression in the ovary of the 0.5-dose TAM-treated test group, although not as frequently observed as in the control group. In general, EGFR expression was not showed significantly difference in oocyte cytoplasm, granulosa cells, interstitial cells, theca cells and corpus luteum of control and experimental groups (Table)

\begin{tabular}{l|l|l|l|l|l}
\hline & \multicolumn{5}{|c}{ Expression Intensity of EGFR } \\
\hline Groups & $\begin{array}{c}\text { Cytoplasm } \\
\text { of Oocytes }\end{array}$ & $\begin{array}{c}\text { Granulosa } \\
\text { Cells }\end{array}$ & $\begin{array}{c}\text { Interstitial } \\
\text { cells }\end{array}$ & $\begin{array}{c}\text { Corpus } \\
\text { Luteum }\end{array}$ & $\begin{array}{l}\text { Theca } \\
\text { Cells }\end{array}$ \\
\hline$\underline{\text { Control }}$ & +++ & - & +++ & ++ & + \\
\hline$\underline{\underline{0,5 T A M}}$ & +++ & - & +++ & ++ & + \\
\hline$\underline{\text { I,5TAM }}$ & +++ & - & +++ & ++ & + \\
\hline
\end{tabular}

Table. Semiquantitative observations of the EGFR immunoreactivity in the mouse ovarium.

\section{Discussion and Conclusion}

In previous studies, it was determined EGFR's expressions by using immunohistochemistry method in human, rat, and hamster ovaries (St. Arnaud et al. 1983, Roy and Greenwald, 1990, Stewart, 1992).

Similar to our findings, previously papers (Ayyagari and Khan-Dawood, 1987, Feng et al. 1987, Garnett et al. 2002, Maruo et al. 1993, Qu et al. 2000) expression of EGFR was detected in oocyte cytoplasm, interstitial cells, theca cells, and corpus luteum. Maruo et al. (1993) showed that in human ovary, there was neither EGF staining nor EGF receptor staining in primordial follicles. These results are consistent with our results. Just like them, in our study there wasn't EGFR expression in the follicle epithelial cells and oocyte cytoplasm of primordial follicle in the all groups. But on the other hand, Qu et al. (2000) have reported that they have an intense EGFR immunoreactivity in the primordial follicles before and after cryopreservation in the human ovary. These findings are in conflict with our findings which we determined there is no expression of EGFR in primordial follicles. Additionally, Moreno-Cuevas and Khan-Dawood (1997) also mentioned that this difference in EGFR expression in the primordial follicles maybe due to sacrificing of animals during different estrus periods. In the present study, the strong immunoreactivity was determined in the oocyte cytoplasm of follicles (from primary follicles to antral follicles) in the all groups and no different between groups. On the contrary, EGFR expression disappears in the granulosa cells of healthy and atretic follicles in the all groups. But on the other hand, unlike our study, Garnett et al. (2002) determined that weak immunoreaction through from primordial follicle to large preantral follicle in the granulosa cells, but in the antral follicles have strong EGFR immunoreactivity. This differences about expression or localization of EGFR reaction may depending on different animal species or different kind of primary antibodies. In the present study, a strong EGFR immunoreactivity was detected in the interstitial area both in the control group and experimental groups. Garnett et al. (2002) also reported that EGFR expression has a moderate to strong immunoreactions in interstitial cells of the hamster ovary. In our study in theca cells of all groups, a weakly intensity EGFR expression was observed. According to Onagbesan et al. (1994) study, EGFR and EGF were also detected in theca cells on the chicken ovary by immunohistochemistry and their levels decreased with follicle maturation (Onagbesan et al. 1994). But in our study we have not observed such a decrease in expression level due to follicular maturation.

As that of Ayyagari and Khan-Dawood's (1987) study, we determined expression of EGFR in the corpus luteum, but there was no significant difference in EGFR expression in the corpus luteum between the control group and the low-dose TAM group. EGFR signaling causes increased proliferation, decreased apoptosis, and enhanced tumor cell motility and neo-angiogenesis (Arteaga, 2002). Furthermore, EGF and its receptor in ovaries during follicular growth and regression was investigated. It was reported that EGF and EGFR was also regulate the function of follicular development (Das et al. 1991, Reeka et al. 1998). In previous studies it was reported that TAM administration suppresses ovarian follicle development but does not 
affect follicle reserve, so that women who have received chemotherapy during premenopause may use TAM for continuation of fertility and ovarian function (Ting and Petrof, 2010). It has also been reported that tamoxifen is antioxidant and anti-apoptotic due to estrogen-like action (Duncan et al. 1994, Nathan and Chaudhuri, 1998). In our study, there was no difference in EGFR expression among the groups after TAM administration. It was observed that the administered doses of TAM have not significant influence on EGFR expression.

Acknowledgments: This work was supported by a grant from TÜBİTAK-TOVAG (The scientific and technological research council of Turkey; project no: 112 O 574).

\section{References}

Arteaga CL. Epidermal growth factor receptor dependence in human tumors: more than just expression? Oncologist, 4: 31-39, 2002.

Ashkenazi H, Cao X, Motola S, Popliker M, Conti M, Tsafriri A. Epidermal growth factor family members: endogenous mediators of the ovulatory response. Endocrinology, 146: 77-84, 2005.

Atalay G, Cardoso F, Awada A, Piccart MJ. Novel therapeutic strategies targeting the epidermal growth factor receptor (EGFR) family and its downstream effectors in breast cancer. Ann Oncol, 14: 1346-1363, 2003.

Ayyagari RR, Khan-Dawood FS. Human corpus luteum: presence of epidermal growth factor receptors and its binding characteristics. Am J Obstet Gynecol, 150: 942-946, 1987.

Bernstein L, Deapen D, Cerhan JR. Tamoksifen therapy for breast cancer and endometrial cancer risk. J Natl Cancer Inst, 91: 1654-1662, 1999.

Blumenfeld Z, Dann E, Avivi R, Epelbaum R, Rowe JM. Fertility after treatment for hodgkin's disease. Ann Oncol, 13: 138-147, 2002.

Clarke M, Cillins R, Davies C. Tamoksifen for early breast cancer: an overview of the randomized trials. Lancet, 351: 1451-1467, 1998.
Crossman GA. Modification of Mallory's Connective Tissue stain with a discussion of the principles involved. Anat Rec, 69(1): 33-38, 1937.

Das K, Stout LE, Hensleigh HC, Tagatz GE, Phipps WR, Leung BS. Direct positive effect of epidermal growth factor on the cytoplasmic maturation of mouse and human oocytes. Fertil Steril, 55: 1000-1004, 1991.

Dowsett M1, Cuzick J, Wale C, Forbes J, Mallon EA, Salter J, Quinn E, Dunbier A, Baum M, Buzdar A, Howell A, Bugarini R, Baehner FL. Shak S. Prediction of risk of distant recurrence using the 21-gene recurrence score in node-negative and node-positive postmenopausal patients with breast cancer treated with anastrozole or tamoxifen: a TransATAC study. J Clin Oncol, 28(11): 1829-1834, 2010.

Duncan MD, Korman LY, Bass BL. Epidermal growth factor primes intestinal epithelial cells for proliferative effect of insulin-like growth factor I. Dig Dis Sci, 39: 2197-201, 1994.

Ekambaram G, Kumar S, Kumar S, Joseph LD. Comparative study on the estimation of estrous cycle in mice by visual and vaginal lavage method. J Clin Diagn Res,11(1): AC05AC07, 2017.

Ergin K, Gursoy E, Bağımoğlu KY, Baġaloğlu H, Seyrek $\mathrm{K}$. Immunohistochemical detection of insulin-like growth factor-I, transforming growth factor-b2, basic fibroblast growth factor and epidermal growth factor-receptor expression in developing rat ovary. Cytokine, 43: 209-214, 2008.

Feng P, Knecht M, Cart K. Hormonal control of epidermal growth factor receptors by gonadotropins during granulosa cell differentiation. Endocrinology, 120: 1121-1128, 1987.

Fisher B, Constantino J, Redmond CK. Endometrial cancer in tamoksifen-treated breast cancer patients: Findings from The National Surgical Adjuvant Breast and Bowel Project (NSABP). J Natl Cancer Inst, 86, 527-537, 1994.

Fong SL, Lugtenburg PJ, Schipper I, Themmen APN, Jong FH, Sonneveld P. Anti-Müllerian hormone as a marker of 
ovarian function in women after chemotherapy and radiotherapy for haematological malignancies. Hum Reprod, 23: 674-678, 2008.

Fromowitz FB, Viola MV, Chao S, Oravez S, Mishriki Y, Finkel G, Grimson R, Lundy J, Ras 21 expression in the progression of breast cancer. Hum Pathol 18: 1268-1275, 1987.

Garnett, K, Wang J, Roy SK. Spatiotemporal expression of epidermal growth factor receptor messenger rna and protein in the hamster ovary: follicle stage-specific differential modulation by follicle-stimulating hormone, luteinizing hormone, estradiol, and progesterone. Biol Reprod, 67: 1593-1604, 2002.

Goldrisch A, Gelber RD. Castiglione M. for the international breast cancer study group. adjuvant therapy of breast cancer. Eur J Cancer, 27: 399-402, 1991.

Gorodeski GI, Beery R, Lunenfeld B, Geier A. Tamoxifen increases plasma estrogen-binding equivalents and has an estradiol agonistic effect on histologically normal premenopausal and post-menopausal endometrium. Fertil Steril, 57: 320-327, 1992.

Herbst RS, Langer CJ. Epidermal growth factor receptors as a target for cancer treatment: The emerging role of IMC-C225 in the treatment of lung and head and neck cancer. Semin Oncol, 29: 27-36, 2002.

Hudson LG, Zeineldin R, Silberberg M, Stack MS. Activated epidermal growth factor receptor in ovarian cancer. Cancer Treat Res, 149: 203-226, 2009.

Jolles CJ, Smotkin D, Ford KL, Jones K.P. Cystic ovarian necrosis complicating tamoxifen therapy for breast cancer in a premenopausal woman: a case report. J Reprod Med, 35: 299-300, 1990.

Jones PBC, Welsh TH, Jr Hsueh AJW. Regulation of ovarian progestin production by epidermal growth factor in cultured rat granulosa cells. J Biol Chem, 257: 11268, 1982.

Jordan V.C. Hoerner S. Tamoxifen and the human carcinoma 8S estrogen receptor. Eur J Cancer, 11: 205-206, 1975.
Jordan VC, O’Malley BW. Selective Estrogen-Receptor Modulators and antihormonal resistance in breast cancer. J Clin Oncol, 25: 5815-5824, 2007.

Knecht M, Catt KJ. Modulation of cAMP-mediated differentiation in ovarian granulosa cells by growth factor and platelet-derived growth factor. J Biol Chem, 258: 2789, 1983.

Lassus H, Sihto H, Leminen A. Gene amplification, mutation, and protein expression of EGFR and mutations of ERBB2 in serous ovarian carcinoma. J Mol Med, 84(8): 671-681, 2006.

Liu JH, Baker J, Perkins A, Robertson E, Efstratiadis A. Mice carrying null mutations of the genes encoding insulin-like growth factor (Igf-1) and Type I IGF receptor (Igf1r). Cell, 75: 59-72, 1993.

Lichtner RB. Estrogen/EGF receptor interactions in breast cancer: rationale for new therapeutic combination strategies. Biomed Pharmacother, 57(10): 447-451, 2003.

Ma XJ, Wang Z, Ryan PD, Isakoff SJ, Barmettler A, Fuller A, Muir B, Mohapatra G, Salunga R, Tuggle JT, Tran Y, Tran D, Tassin A, Amon P, Wang W, Enright E, Stecker K, Sgroi DC. A two-gene expression ratio predicts clinical outcome in breast cancer patients treated with tamoxifen. Cancer Cell, 5(6): 607-616, 2004.

MacGregor JI, Jordan VC. Basic guide to the mechanisms of antiestrogenaction. Pharmacol Rev, 50(2): 151-196, 1998.

Maruo T, Ladines-Llave CA, Samoto T, Matsuo H, Manalo AS, Ito H, Mochizuki M. Expression of epidermal growth factor and its receptor in the human ovary during follicular growth and regression. Endocrinology, 132(2): 924-31, 1993.

Meirow D, Nugent D. The effects of radiotherapy and chemotherapy on female reproduction. Hum Reprod Update, 7: 535-543, 2001.

Moreno-Cuevas, J, Khan-Dawood FS. Epidermal growth factor receptors in rat ovarian tissue. Tissue \& Cell, 29(1): 55-62,1997. 
Nathan L, Chaudhuri G. Antioxidant and prooxidant actions of estrogens: potential physiological and clinical implications. Semin Reprod Endocrinol, 16: 309-314, 1998.

Onagbesan OM, Gullick W, Woolveridge I, Peddie MJ. Immunohistochemical localization of epidermal growth factor receptors, epidermal-growth-factor-like and transforming-growth-factor-a-like peptides in chicken ovarian follicles. J Reprod Fertil, 102: 147-153, 1994.

Qu J, Godin PA, Nisolle M, Donmez J. Distribution and epidermal growth factor receptor expression of primordial follicle in human ovarian tissue before and after cryopreservation. Hum Reprod, 15(2): 302-310, 2000.

Reeka N, Berg FD, Brucker C. Presence of transforming growth factor alpha and epidermal growth factor in human ovarian tissue and follicular fluid. Hum Reprod, 13:(8) 2199-2205, 1998.

Roy SK, Greenwald GS. Immunohistochemical localization of epidermal growth factor-like activity in the hamster ovary with a polyclonal antibody. Endocrinology, 126: 1309-1317, 1990.

Rutqvist LE, Johansson H, Signomklao T, Johansson U, Fornader T, Wilking N. Adjuvant tamoxifen therapy for early stage breast cancer and second primary malignancies. J Natl Cancer Inst, 87: 645-650, 1995.

Salomon DS, Brandt R, Ciardiello F. Epidermal growth factor-related peptides and their receptors in human malignancies. Crit Rev Oncol Hematol, 19: 183-232, 1995.

Shang Y, Brown M. Molecular determinants for the tissue specificity of SERMs. Science, 295, 2465-2468, 2002.

Spinelli G, Bardozzi N, Citernessi A, Fontonarosa M, Curiel P. Endometrial carcinoma in tamoxifen treated cancer patients. J Chemother, 3: 267-270, 1991.

St. Arnaud R, Walker P, Kelley PA, Labrie E. Rat ovarian epidermal growth factor receptors: characterization and hormonal regulation. Mol Cell Endocrinol, 31: 43-56. 1983. receptor status in primary and recurrent ovarian cancer. Modern Pathology, 19(4): 607-610, 2006.

Stewart CJ. Expression of EGFr in normal ovary and in ovarian tumors. Int J Gynecol Pathol, 11: 266-272, 1992.

Sunderland MC, Osborne CK. Tamoxifen in premenopausal patients with metastatic breast cancer: A review. J Clin Oncol, 9: 1283-1297, 1991.

Ting AY, Petroff BK. Tamoxifen decreases ovarian follicular loss from experimental toxicant DMBA and chemotherapy agents cyclophosphamide and doxorubicin in the rat. J Assist Reprod Genet, 27(11): 591-597, 2010.

Uberal, I, Kolar Z, Trojanec R, Berkovcova J, Hajduch M. The status and role of ErbB receptors in human cancer. Exp Mol Pathol, 84: 79-89, 2008.

Vlodavsky I, Brown KD, Gospodarowicz D. A comparison of the binding of epidermal growth factor to cultured granulosa and luteal cells. J Biol Chem, 253: 3744, 1978.

Yarden Y, Pines G. The ERBB network: at last, cancer therapy meets systems biology. Nat Rev Cancer, 12: 553-563, 2002. 